advocacy efforts, but is dependent on the active participation and leadership of STFM members. Congress listens to those who provide care and teach. Here is what our colleagues say about advocacy

Dan Lasser, MD, Chair, University of Massachusetts: "When you start doing this, you learn that the members of Congress and other people who are involved with policy actually do want to hear from constituents and people that have concerns about health policy and we have a lot to offer to the whole legislative and health policy process."

Jeffrey Borkan, MD, PhD, Chair, Brown University: "If we are not out there [advocating], we are going to continue to have a medical system that looks the way it is, if we are not out there, people are not going to get care."

Jeffrey Cain, MD, Denver, CO: "The same lessons we learn for teaching medical students work for teaching legislators."

What these colleagues realize is that advocacy starts from the heart, with a message for better healthcare-and the process flows easily from there. Dr Cain continued his earlier comments, "I didn't start out being an advocate I just wanted to help protect kids from tobacco. We started doing Tar Wars and found out those lessons we learned about advocacy with kids health transferred into legislative advocacy too".

Likewise, Dr Kruse, the current chair of the STFM Legislative Affairs Committee, didn't start as an advocate. With the encouragement of colleagues, he became involved in ADFM and STFM advocacy, and can speak to the rewards of advocacy through the development of relationships with people in the offices of senators and representatives. Because family physicians are armed with the strongest and most elegant data, it generally takes only a few visits to become a trusted healthcare advisor to the legislators and their staff.

STFM has much to offer to help you develop skills in advocacy. The DC office is there to help. Please call our staff in Washington about any question you may have about the legislative process, or about specific legislation, policies, or advocacy tips. We salute those who are committed to advocacy, and ask for continued involvement. We ask a new generation of advocates to step forward to amplify the message. If you do, health and health care in the United States will improve.

Hope Wittenberg, MA

STFM Director, Government Relations Jerry Kruse, MD, MSPH

Chair, STFM Legislative Affairs Committee

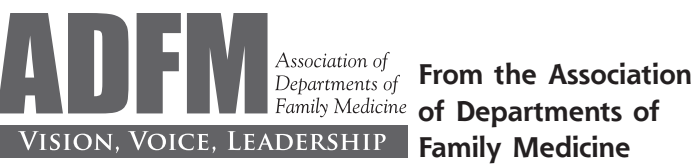

Ann Fam Med 2010;8:184-185. doi.10.1370/afm.1100.

\section{How to Manage the Pace of Practice Innovation Information Flow and Change? Introducing the ADFM Patient Centered Medical Home Taskforce}

These are exciting times for family medicine/primary care, and departments of family medicine are increasingly engaged in clinical innovation in order to meet the needs of our patients and our discipline. ${ }^{1}$ Keeping up with the rapid flow of information and change presents a major challenge: How to coordinate the active and ever-moving dialogues regarding PCMH with local, regional and national leaders, and garner insights from the cacophony of demonstration projects and initiatives into useable information for our members and their departments? How do we incorporate all of the missions of academic departments (clinical, educational and scholarship) into curricular redesign and clinical effectiveness research, in addition to the clinical practice transformation required?

As described in the Nov/Dec 2009 issue of the Annals of Family Medicine, ADFM is working with the Patient Centered Primary Care Collaborative (PCPCC) to further our own departments' strengths and evolution in clinical areas related to the Patient Centered Medical Home (PCMH). However, even within this one organization there is an ever increasing number of initiatives, centers, communication mechanisms, and publications, from which are a host of emerging allied enterprises, Web sites, and resources. ADFM leadership is desirous of creating an ongoing method for distilling down the breadth of this rapidly moving target, as well as to utilize the talents of our members to create a proactive dialogue of ideas and information back to PCPCC and other PCMH entities. To accomplish this, a new PCMH task force in ADFM has been formed to support, stimulate and monitor this synergistic exchange between Departments of Family Medicine and the Patient Centered Primary Care Collaborative, NCQA, CAFM, and other groups with similar activities. The overarching goal of the task force is to facilitate ADFM and family medicine playing an active role in the evolving PCMH domain, with 3 specific objective as illustrated below:

1. Information Clearinghouse - to serve as a source 
of information to the ADFM membership re: $\mathrm{PCMH}$ activities, resources, advocacy issues, etc.

2. Proactive Advocacy Role ("Strike Force" or "Rapid Response Team") - to identify PCMH task force and other ADFM members to be available to serve as contributors/informants among the many constituent groups that are working at the national level on primary care transformation related to medical homes.

3. Mission Integration - to go beyond traditional ADFM Clinical Committee functions, in order to integrate clinical transformation with our educational programs and our outcomes research; this is what makes our contributions unique as academic departments. Task force membership would include members of each ADFM standing committee (Clinical, Research Development, Medical Student Education, Residency, Legislative Affairs, etc). The goal would be to integrate missions across areas and topics in a synergistic, complementary manner.
The PCMH task force has its work cut out for it. It must formalize and modify its charge as conditions change, coordinate among its members, the ADFM officers, board, and the entirety of ADFM membership, and communicate both internally and externally. A set of deliverables for this group is expected to be presented after the ADFM Winter meeting in late February 2010, and will be posted to the ADFM Web site. Becoming an active force in shaping the evolution of this movement is the penultimate task; with the ultimate goal of better serving and improving the healthcare needs of the US populations. Libby Baxley, $M D_{i}$ Jeffrey Borkan, $M D, P b D_{i}$ Ardis Davis, MSW, and the ADFM Executive Committee

\section{References}

1. Borkan, J, Magill M, Schenk MJ, Davis A: Out of the ivory tower: engaging the national dialogue on the patient centered medical home. Ann Fam Med. 2009;7(6):566-567.

\section{Correction}

Ann Fam Med 2009;8:99. doi:10.1370/afm.1106.

In the 2010 January/February print issue of the Annals, there were 2 instances in which references were omitted from an article. These 2 articles therefore depart from those published in the online version of the issue.

The following references were omitted from Frey JJ III. In this issue: race, place, and sex matter. Ann Fam Med. 2010;8(1)2-3.

10. van Doormaal FF, Atalay S, Brouwer $\mathrm{H}$, van der Velde $\mathrm{E}$, Bller $\mathrm{H}$, van Weert HC. Idiopathic superficial thrombophlebitis and the incidence of cancer in primary care patients. Ann Fam Med. 2010;8(1):47-50.

11. Korb K, Scherer M, Chenot JF. Steroids as adjuvant therapy for acute pharyngitis in ambulatory patients: a systematic review. Ann Fam Med. 2010;8(1):58-63.

12. Perera CL, Bridgewater FHG, Thavaneswaran P, Maddern GJ. Safety and efficacy of nontherapeutic male circumcision: a systematic review. Ann Fam Med. 2010;8(1):64-72.

The following reference was omitted from Stange KC. Actionable ideas to improve health care and health. Ann Fam Med. 2010;8(1):82-84.

28. Stange KC, Ferrer RL, Miller WL. Making sense of health care transformation as adaptive-renewal cycles. Ann Fam Med. $2009 ; 7(6): 484-487$. 